\title{
A control strategy for stand-alone wound rotor induction machine
}

\author{
D.G. Forchetti ${ }^{\mathrm{a}, *}$, J.A. Solsona ${ }^{\mathrm{b}}$, G.O. García ${ }^{\mathrm{a}}$, M.I. Valla ${ }^{\mathrm{c}}$ \\ a Grupo de Electrónica Aplicada (GEA), Universidad Nacional de Río Cuarto, X5804 BYA Río Cuarto, Argentina \\ b Instituto de Investigaciones en Ingeniería Eléctrica “Alfredo Desages”, Departamento de Ingeniería Eléctrica y de Computadoras, \\ Universidad Nacional del Sur, Bahia Blanca, Argentina \\ ${ }^{\mathrm{c}}$ Laboratorio de Electrónica Industrial, Control e Instrumentación (LEICI), Facultad de Ingeniería, Universidad Nacional de La Plata, \\ 1900 La Plata, Argentina
}

Received 24 May 2005; received in revised form 20 February 2006; accepted 21 February 2006

Available online 4 April 2006

\begin{abstract}
A control strategy to regulate the frequency and voltage of a stand-alone wound rotor induction machine is presented. This strategy allows the machine to work as a generator in stand-alone systems (without grid connection) with variable rotor speed. A stator flux-oriented control is proposed using the rotor voltages as actuation variables. Two cascade control loops are used to regulate the stator flux and the rotor currents. A closed loop observer is designed to estimate the machine flux which is necessary to implement these control loops. The proposed control strategy is validated through simulations with satisfactory results.
\end{abstract}

(c) 2006 Elsevier B.V. All rights reserved.

Keywords: Wound rotor induction machine; Variable speed constant frequency; Stand-alone (autonomous) generator

\section{Introduction}

Variable speed generating systems show better efficiency than constant speed generating systems when the primary source of energy is variable [1,2]. This is the case for the generating systems that uses renewable energies like wind, geothermal, hydro, etc.

Those systems can be used to complement other energy generating systems connected to the grid (co-generating systems). In these cases, the grid imposes the frequency and voltage, and the generator control takes care of other tasks like active and reactive power control $[3,4]$ or energy conversion optimization $[5,6]$.

In those cases where the users are far away from the grid and cannot reach the energy provided by it, a stand-alone (isolated) generating system can be used [7]. This kind of systems must be able to provide the users with regulated voltage and frequency [8]. In these cases, wound rotor induction machines (WRIM) present several advantageous characteristics working at variable speed while regulating the generated voltage and frequency [9$11]$.

\footnotetext{
* Correspondence to: D.G. Forchetti, Grupo de Electrónica Aplicada, Fac. de Ingeniería UNRC, Ruta Nac. 26 km 601, X584BYA Río Cuarto, Córdoba, Argentina. Tel.: +54 358 4676255; fax: +54 3584676246 .

E-mail address: dforchetti@ing.unrc.edu.ar (D.G. Forchetti).
}

WRIM supplying isolated loads can be found in refs. [12-15], where the application feasibility of this machine on stand-alone systems is analyzed. In refs. [16-18], Kawabata et al. propose two cascade loops to control the rotor current and stator voltage. The rotor current control loop is realized using two linear controller with feed forward compensating terms and the stator voltage is realized using a lineal controller with a non-linear feedback. In refs. [19-21], Peña et al. propose an indirect voltage and frequency control achieved by controlling the stator flux while neglecting the stator resistance and imposing slip frequency to the rotor currents through an algebraic relationship.

Using an algebraic relationship to calculate the stator flux, based on the stator and rotor currents, can be considered as to estimate the stator flux using an open loop observer. It is well known that the use of these kind of observers might present significant estimation errors when model uncertainties are present [22]. Then, the use of a closed loop observer is a good choice to improve the steady state and transient behavior of the control system.

In this paper, a control strategy to regulate the frequency and voltage of a WRIM working as a variable speed stand-alone generating system is proposed. A closed loop observer is designed to estimate the stator flux. The paper is organized as follows: the WRIM model is presented in Section 2. The proposed control loops, including the closed loop observer, are presented in 
Section 3. The control performance is evaluated through simulations in Section 4. Finally, conclusions are given in Section 5 .

\section{WRIM model}

The WRIM can be described by the following equations using a dq reference frame rotating at an arbitrary speed $\omega_{\mathrm{dq}}$ [23]:

$\frac{\mathrm{d} \lambda_{\mathrm{qs}}}{\mathrm{d} t}=-\frac{1}{\tau_{\mathrm{s}}} \lambda_{\mathrm{qs}}-\omega_{\mathrm{dq}} \lambda_{\mathrm{ds}}+\frac{M}{\tau_{\mathrm{s}}} i_{\mathrm{qr}}+v_{\mathrm{qs}}$
$\frac{\mathrm{d} \lambda_{\mathrm{ds}}}{\mathrm{d} t}=+\omega_{\mathrm{dq}} \lambda_{\mathrm{qs}}-\frac{1}{\tau_{\mathrm{s}}} \lambda_{\mathrm{ds}}+\frac{M}{\tau_{\mathrm{s}}} i_{\mathrm{dr}}+v_{\mathrm{ds}}$

$\frac{\mathrm{d} i_{\mathrm{qr}}}{\mathrm{d} t}=\frac{\beta}{\tau_{\mathrm{s}}} \lambda_{\mathrm{qs}}+\beta \omega_{\mathrm{r}} \lambda_{\mathrm{ds}}-\gamma_{2} i_{\mathrm{qr}}-\left(\omega_{\mathrm{dq}}-\omega_{\mathrm{r}}\right) i_{\mathrm{dr}}-\beta v_{\mathrm{qs}}$

$$
+\frac{1}{\sigma L_{\mathrm{r}}} v_{\mathrm{qr}}
$$

$$
\begin{aligned}
\frac{\mathrm{d} i_{\mathrm{dr}}}{\mathrm{d} t}= & -\beta \omega_{\mathrm{r}} \lambda_{\mathrm{qs}}+\frac{\beta}{\tau_{\mathrm{s}}} \lambda_{\mathrm{ds}}+\left(\omega_{\mathrm{dq}}-\omega_{\mathrm{r}}\right) i_{\mathrm{qr}}-\gamma_{2} i_{\mathrm{dr}}-\beta v_{\mathrm{ds}} \\
& +\frac{1}{\sigma L_{\mathrm{r}}} v_{\mathrm{dr}} .
\end{aligned}
$$

where $\lambda_{\mathrm{qs}}, \lambda_{\mathrm{ds}}, i_{\mathrm{qr}}, i_{\mathrm{dr}}$ are the stator fluxes and the rotor currents, $v_{\mathrm{qs}}, v_{\mathrm{ds}}, v_{\mathrm{qr}}, v_{\mathrm{dr}}$ the stator and rotor voltages, respectively, $L_{\mathrm{s}}$ and $L_{\mathrm{r}}$ the stator and rotor inductances, $\omega_{\mathrm{r}}$ the rotor mechanical speed, $M$ the magnetizing inductance and

$$
\begin{aligned}
\sigma & =1-\frac{M^{2}}{L_{\mathrm{r}} L_{\mathrm{s}}}, \quad \beta=\frac{1-\sigma}{M \sigma}, \quad \tau_{\mathrm{s}}=\frac{L_{\mathrm{s}}}{r_{\mathrm{s}}}, \quad \tau_{\mathrm{r}}=\frac{L_{\mathrm{r}}}{r_{\mathrm{r}}}, \\
\gamma_{2} & =\left(\frac{1-\sigma}{\sigma \tau_{\mathrm{s}}}+\frac{1}{\sigma \tau_{\mathrm{r}}}\right),
\end{aligned}
$$

where $r_{\mathrm{s}}$ and $r_{\mathrm{r}}$ are the stator and rotor resistances.

\section{Proposed control}

The objective of this paper is to propose a strategy to implement a generator system using a WRIM. This strategy is designed to regulate the machine stator voltage and frequency. The voltage regulation is achieved, indirectly, by controlling the stator flux vector magnitude and angular speed. The frequency regulation is achieved by keeping the flux vector aligned with a dq reference frame rotating at synchronous speed $\left(\omega_{\mathrm{dq}}=\right.$ $314 \mathrm{rad} / \mathrm{s}$ ), consequently,

$\lambda_{\mathrm{qs}}=0$.

While the stator flux vector remains aligned as defined in Eq. (5), the flux magnitude can be calculated as its direct component $\lambda_{\mathrm{ds}}$.

It can be observed in Eqs. (1) and (2) that the rotor currents $\left(i_{\mathrm{qr}}, i_{\mathrm{dr}}\right)$ can be used to control the machine flux components. Moreover, Eqs. (3) and (4) show that the rotor currents can be controlled by using the rotor voltages $\left(v_{\mathrm{qr}}, v_{\mathrm{dr}}\right)$. Therefore, two cascade control loops can be implemented, one internal to control the rotor currents and the other one external to control the stator flux components.

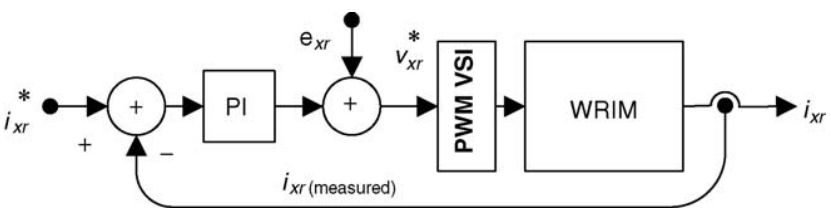

Fig. 1. Current control loop $(x=\mathrm{d}, \mathrm{q})$.

\subsection{Current control loop}

Fig. 1 shows a block diagram of the proposed current control loop.

A PI compensator plus a feed forward compensating term, $\mathrm{e}_{x \mathrm{r}}$, is proposed to generate the rotor voltage reference $\left(v_{x}^{*}\right)$ used in the Pulse Width Modulated-Voltage Source Inverter (PWMVSI),

$v_{\mathrm{qr}}^{*}=\sigma L_{\mathrm{r}}\left[k_{\mathrm{p}}\left(i_{\mathrm{qr}}^{*}-i_{\mathrm{qr}}\right)+k_{\mathrm{i}} x_{\mathrm{qr}}\right]+\mathrm{e}_{\mathrm{qr}}$

$v_{\mathrm{dr}}^{*}=\sigma L_{\mathrm{r}}\left[k_{\mathrm{p}}\left(i_{\mathrm{dr}}^{*}-i_{\mathrm{dr}}\right)+k_{\mathrm{i}} x_{\mathrm{dr}}\right]+\mathrm{e}_{\mathrm{dr}}$,

where $x_{\mathrm{qr}}$ and $x_{\mathrm{dr}}$ are the auxiliary variables used to implement the integral control,

$\frac{\mathrm{d} x_{\mathrm{qr}}}{\mathrm{d} t}=i_{\mathrm{qr}}^{*}-i_{\mathrm{qr}}$

$\frac{\mathrm{d} x_{\mathrm{dr}}}{\mathrm{d} t}=i_{\mathrm{dr}}^{*}-i_{\mathrm{dr}}$,

$i_{\mathrm{qr}}^{*}$ and $i_{\mathrm{dr}}^{*}$ are the rotor current references, and $k_{\mathrm{p}}$ and $k_{\mathrm{i}}$ are the PI proportional and integral gains. These gains are chosen so that the rotor current control loop is faster than the stator flux control loop. However, there are two trade-offs for the desired loop speed: one with the inverter switching frequency which should be higher than the cut-off of the control loop, and a second one with the available control action, defined as the maximum voltage supported by the rotor windings (voltage saturation).

The feed forward compensating term, added to the PI compensator output, is used to cancel the non-linear terms $\left(\left(\omega_{\mathrm{dq}}-\right.\right.$ $\left.\omega_{\mathrm{r}}\right) i_{\mathrm{dr}},\left(\omega_{\mathrm{dq}}-\omega_{\mathrm{r}}\right) i_{\mathrm{qr}}, \beta \omega_{\mathrm{r}} \lambda_{\mathrm{qs}}$ and $\left.\beta \omega_{\mathrm{r}} \lambda_{\mathrm{ds}}\right)$ and to reject the perturbations introduced by the stator voltages $\left(\beta v_{\mathrm{qs}}\right.$ and $\left.\beta v_{\mathrm{ds}}\right)$ and fluxes $\left(\beta / \tau_{\mathrm{s}} \lambda_{\mathrm{qs}}\right.$ and $\left.\beta / \tau_{\mathrm{s}} \lambda_{\mathrm{ds}}\right)$, shown in Eqs. (3) and (4). This compensating term can be deduced from the machine model, yielding to the following expression,

$\mathrm{e}_{\mathrm{qr}}=\sigma L_{\mathrm{r}}\left(\left(\omega_{\mathrm{dq}}-\omega_{\mathrm{r}}\right) i_{\mathrm{dr}}+\beta\left(-\lambda_{\mathrm{qs}} \frac{1}{\tau_{\mathrm{s}}}-\lambda_{\mathrm{ds}} \omega_{\mathrm{r}}+v_{\mathrm{qs}}\right)\right)$
$\mathrm{e}_{\mathrm{dr}}=\sigma L_{\mathrm{r}}\left(-\left(\omega_{\mathrm{dq}}-\omega_{\mathrm{r}}\right) i_{\mathrm{qr}}+\beta\left(+\lambda_{\mathrm{qs}} \omega_{\mathrm{r}}-\lambda_{\mathrm{ds}} \frac{1}{\tau_{\mathrm{s}}}+v_{\mathrm{ds}}\right)\right)$.

Using this control strategy and assuming that the PWM-VSI is not saturated, the closed loop dynamics corresponds to a firstorder linear system plus a PI controller, where $x_{\mathrm{qr}}$ and $x_{\mathrm{dr}}$ are defined in Eqs. (8) and (9),

$\frac{\mathrm{d} i_{\mathrm{qr}}}{\mathrm{d} t}=-\gamma_{2} i_{\mathrm{qr}}+k_{\mathrm{p}}\left(i_{\mathrm{qr}}^{*}-i_{\mathrm{qr}}\right)+k_{\mathrm{i}} x_{\mathrm{qr}}$
$\frac{\mathrm{d} i_{\mathrm{dr}}}{\mathrm{d} t}=-\gamma_{2} i_{\mathrm{dr}}+k_{\mathrm{p}}\left(i_{\mathrm{dr}}^{*}-i_{\mathrm{dr}}\right)+k_{\mathrm{i}} x_{\mathrm{dr}}$. 
The transfer function of the system can be obtained by applying the Laplace transform to Eqs. (12) and (13). This transfer function has two poles and one zero. The control gains, $k_{\mathrm{p}}$ and $k_{\mathrm{i}}$, can be selected such as the lower pole is cancelled by the zero. It results in a first-order system. By making $k_{\mathrm{i}}=k_{\mathrm{p}} \gamma_{2}$, the current dynamics can be described as follows:

$\frac{\mathrm{d} i_{\mathrm{qr}}}{\mathrm{d} t}=-k_{\mathrm{p}} i_{\mathrm{qr}}+k_{\mathrm{p}} i_{\mathrm{qr}}^{*}$

$\frac{\mathrm{d} i_{\mathrm{dr}}}{\mathrm{d} t}=-k_{\mathrm{p}} i_{\mathrm{dr}}+k_{\mathrm{p}} i_{\mathrm{dr}}^{*}$

With the objective of controlling the system, also under rotor voltage saturation conditions, the proposed PI compensator is modified using a proportional integral anti windup strategy. Fig. 2 shows the compensator, similar to those given by [24], with the additional feed forward compensating term proposed in this paper, where a saturation voltage is fixed at 1.7 p.u. according to the available DC bus voltage.

\subsection{Flux control loop}

To use the rotor current as the manipulated variable in the stator flux control loop, the current control loop is designed much faster than the stator flux control loop. Under this consideration, the rotor currents and its reference values will be considered equal.

The stator flux dynamics, defined by Eqs. (1) and (2), can be expressed in matrix form as follows,

$\dot{\lambda}_{\mathrm{s}}=\mathbf{H}_{\mathrm{s}} \lambda_{\mathrm{s}}+\mathbf{M}_{\mathrm{s}} \mathbf{i}_{\mathrm{r}}+\mathbf{v}_{\mathrm{s}}$,

where

$\mathbf{H}_{\mathrm{s}}=\omega_{\mathrm{dq}} \mathbf{J}-1 / \tau_{\mathrm{s}} \mathbf{I}, \quad \mathbf{M}_{\mathrm{s}}=M / \tau_{\mathrm{s}} \mathbf{I}$,

$\lambda_{\mathrm{s}}=\left[\begin{array}{c}\lambda_{\mathrm{qs}} \\ \lambda_{\mathrm{ds}}\end{array}\right], \quad \mathbf{i}_{\mathrm{r}}=\left[\begin{array}{c}i_{\mathrm{qr}} \\ i_{\mathrm{dr}}\end{array}\right] \quad$ and $\quad \mathbf{v}_{\mathrm{s}}=\left[\begin{array}{c}v_{\mathrm{qs}} \\ v_{\mathrm{ds}}\end{array}\right]$.

The reference flux dynamic is defined as follows,

$\dot{\lambda}_{\mathrm{s}}^{*}=\mathbf{H}_{\mathrm{s}} \lambda_{\mathrm{s}}+\mathbf{M}_{\mathrm{s}} \mathbf{i}_{\mathrm{r}}+\mathbf{v}_{\mathrm{s}}+\mathbf{R}\left(\lambda_{\mathrm{s}}^{*}-\lambda_{\mathrm{s}}\right)$,

where $\mathbf{R}$ is a constant coefficients square matrix, whose coefficients have to be chosen according to the desirable stator flux control loop speed. Solving Eq. (17) for the rotor current, yields to,

$\mathbf{i}_{\mathrm{r}}=\mathbf{M}_{\mathrm{s}}^{-1}\left[\dot{\lambda}_{\mathrm{s}}^{*}-\mathbf{H}_{\mathrm{s}} \lambda_{\mathrm{s}}-\mathbf{v}_{\mathrm{s}}-\mathbf{R}\left(\lambda_{\mathrm{s}}^{*}-\lambda_{\mathrm{s}}\right)\right]$.

The existence of $\mathbf{M}_{\mathrm{s}}^{-1}$ is guaranteed since $\mathbf{M}_{\mathrm{s}}$ is a diagonal matrix whose elements are never zero. Substituting Eq. (18) in

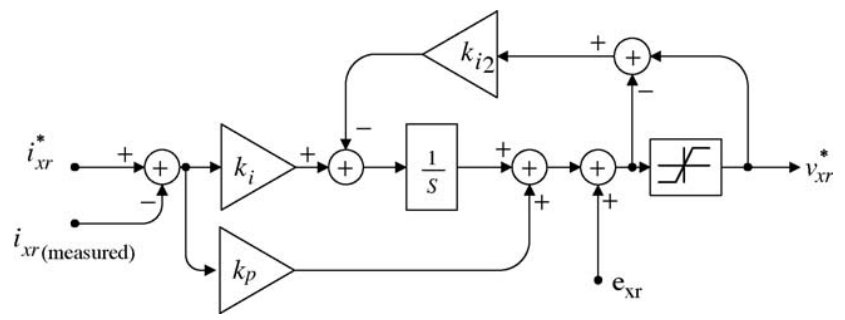

Fig. 2. PI with anti windup and feed forward compensating term.
(16), the following equation can be obtained,

$\dot{\lambda}_{\mathrm{s}}=\dot{\lambda}_{\mathrm{s}}^{*}-\mathbf{R}\left(\lambda_{\mathrm{s}}^{*}-\lambda_{\mathrm{s}}\right)$.

The stator flux control error $\left(\mathbf{e}_{\lambda}\right)$ is defined as,

$\mathbf{e}_{\lambda}=\lambda_{\mathrm{s}}^{*}-\lambda_{\mathrm{s}}$,

then, by differentiating Eq. (20) and using (19), the stator flux error dynamics can be obtained as,

$\dot{\mathbf{e}}_{\lambda}=\mathbf{R} \mathbf{e}_{\lambda}$.

Therefore, choosing $\mathbf{R}$ as follows,

$\mathbf{R}=\left[\begin{array}{cc}\sigma_{\lambda \mathrm{q}} & 0 \\ 0 & \sigma_{\lambda \mathrm{d}}\end{array}\right] \quad$ with $\quad \sigma_{\lambda \mathrm{q}}<0 \quad$ and $\quad \sigma_{\lambda \mathrm{d}}<0$,

it is possible to guarantee that the origin $\left(\mathbf{e}_{\lambda}=0\right)$ is an asymptotically stable equilibrium point.

The control law obtained in Eq. (18), requires the reference flux derivative, therefore the flux reference functions must have their first and second derivatives bounded in order to obtain bounded control actions.

\subsection{Flux observer}

The direct measurement of the WRIM flux can only be carried out in special machines that either have sensors among their windings or that have been modified to shelter special sensors. Another alternative is to use a closed loop observer to estimate the stator flux, avoiding the need of using special sensors [22].

Using Eq. (16), it is possible to build the following observer,

$\dot{\hat{\lambda}}_{\mathrm{s}}=\mathbf{H}_{\mathrm{s}} \hat{\lambda}_{\mathrm{s}}+\mathbf{M}_{\mathrm{s}} \mathbf{i}_{\mathrm{r}}+\mathbf{v}_{\mathrm{s}}+\mathbf{G}\left(\hat{\lambda}_{\mathrm{s}}-\lambda_{\mathrm{s}}\right)$

with

$\mathbf{G}=\left[\begin{array}{ll}g_{11} & g_{12} \\ g_{21} & g_{22}\end{array}\right]$ and $\hat{\lambda}=\left[\begin{array}{l}\hat{\lambda}_{\mathrm{qs}} \\ \hat{\lambda}_{\mathrm{ds}}\end{array}\right]$ the estimates.

Due to the fact that the stator flux $\left(\lambda_{\mathrm{s}}\right)$ cannot be measured to implement the correction term in Eq. (23), the following equations that relate stator flux and stator and rotor currents can be used to calculate it,

$\lambda_{\mathrm{s}}=\mathbf{L}_{\mathrm{s}} \mathbf{i}_{\mathrm{s}}+\mathbf{M i}_{\mathrm{r}}$,

where

$\mathbf{L}_{\mathrm{s}}=L_{\mathrm{s}} \mathbf{I}$ and $\quad \mathbf{M}=M \mathbf{I}$.

Then, the observer Eq. (23) becomes,

$\dot{\hat{\lambda}}_{\mathrm{s}}=\mathbf{H}_{\mathrm{s}} \hat{\lambda}_{\mathrm{s}}+\mathbf{M}_{\mathrm{s}} \mathbf{i}_{\mathrm{r}}+\mathbf{v}_{\mathrm{s}}+\mathbf{G}\left(\hat{\lambda}_{\mathrm{s}}-\mathbf{L}_{\mathrm{s}} \mathbf{i}_{\mathrm{s}}-\mathbf{M i}_{\mathrm{r}}\right)$.

From Eqs. (16) and (27), it is possible to obtain the observation error dynamics as follows,

$\dot{\mathbf{e}}_{0}=\left(\mathbf{H}_{\mathrm{s}}+\mathbf{G}\right) \mathbf{e}_{0}$.

The elements of $\mathbf{G}$ can be chosen so as to make the origin $\left(\mathbf{e}_{0}=0\right)$ an asymptotically stable equilibrium point, with the 
Table 1

Model parameters

\begin{tabular}{lclc}
\hline Parameter & Value & Parameter & Value \\
\hline$P_{\text {(rated) }}(\mathrm{kW})$ & 5.5 & $v_{\mathrm{r}(\text { saturation })}(\mathrm{V})$ & 333 \\
$v_{\mathrm{S}(\text { rated })}(\mathrm{V})$ & 220 & $L_{\mathrm{s}}=L_{\mathrm{r}}(\mathrm{mH})$ & 122.8 \\
$v_{\mathrm{r}(\mathrm{rated})}(\mathrm{V})$ & 132 & $M(\mathrm{mH})$ & 121 \\
$i_{\mathrm{s} \text { (rated) }}(\mathrm{A})$ & 12 & $r_{\mathrm{s}}(\Omega)$ & 0.67 \\
$i_{\mathrm{r}(\mathrm{rated})}(\mathrm{A})$ & 16 & $r_{\mathrm{r}}(\Omega)$ & 1.17 \\
$\lambda_{\mathrm{s}(\text { rated })}(\mathrm{V} \mathrm{s})$ & 1 & $\omega_{\mathrm{b}}(\mathrm{rad} / \mathrm{s})$ & 314 \\
\hline
\end{tabular}

desired speed of convergence. In this way, it is possible to find $\left(g_{i j} i, j=1,2\right)$ so that,

$\mathbf{H}_{\mathrm{s}}+\mathbf{G}=\left[\begin{array}{ll}\sigma_{\mathrm{oq}} & 0 \\ 0 & \sigma_{\mathrm{od}}\end{array}\right] \quad$ with $\quad \sigma_{\mathrm{oq}}<0 \quad$ and $\quad \sigma_{\mathrm{od}}<0$,

where the resultant gains are,

$\mathbf{G}=\left[\begin{array}{cc}1 / \tau_{\mathrm{s}}+\sigma_{\mathrm{oq}} & \omega_{\mathrm{dq}} \\ -\omega_{\mathrm{dq}} & 1 / \tau_{\mathrm{s}}+\sigma_{\mathrm{od}}\end{array}\right]$

Due to the fact that the flux estimate is used in the current control loop as well as in the flux control loop, the observer must be faster than any of these control loops. However, this speed cannot be increased indefinitely because it should satisfy the trade-off between the convergence speed and the measurement noise rejection capability of the observer.

\section{Simulation results}

Fig. 3 shows a simplified block diagram of the proposed control system. The rotor current compensator, the flux compensator and the flux observer are shown in this figure.

The capacitor bank, connected to the generator terminals $(C=50 \mu \mathrm{F})$ is designed taking three premises into account: filter the high frequency commutation noise induced by the rotor PWM-VSI, smooth the voltage peak that may appear after a sudden change of load on the generator terminals and provide at least part of the magnetizing current reducing the current required to the rotor.

The following results were obtained from simulations of the proposed system using the parameters listed in Table 1 . The gains of the control loops and the observer used to obtain such results are listed in Table 2. The rotor speed was fixed in 0.7 p.u. for the simulation shown.
Table 2

System gains

\begin{tabular}{llll}
\hline Parameter & Value & Parameter & Value \\
\hline$\sigma_{\mathrm{oq}}$ & $-5 \times 10^{4}$ & $k_{\mathrm{i}}$ & $1.65 \times 10^{4}$ \\
$\sigma_{\mathrm{od}}$ & $-5 \times 10^{4}$ & $k_{\mathrm{p}}$ & $8.25 \times 10^{6}$ \\
$\sigma_{\lambda \mathrm{q}}$ & -500 & $k_{\mathrm{i} 2}$ & $4.5 \times 10^{11}$ \\
$\sigma_{\lambda \mathrm{d}}$ & -500 & & \\
\hline
\end{tabular}
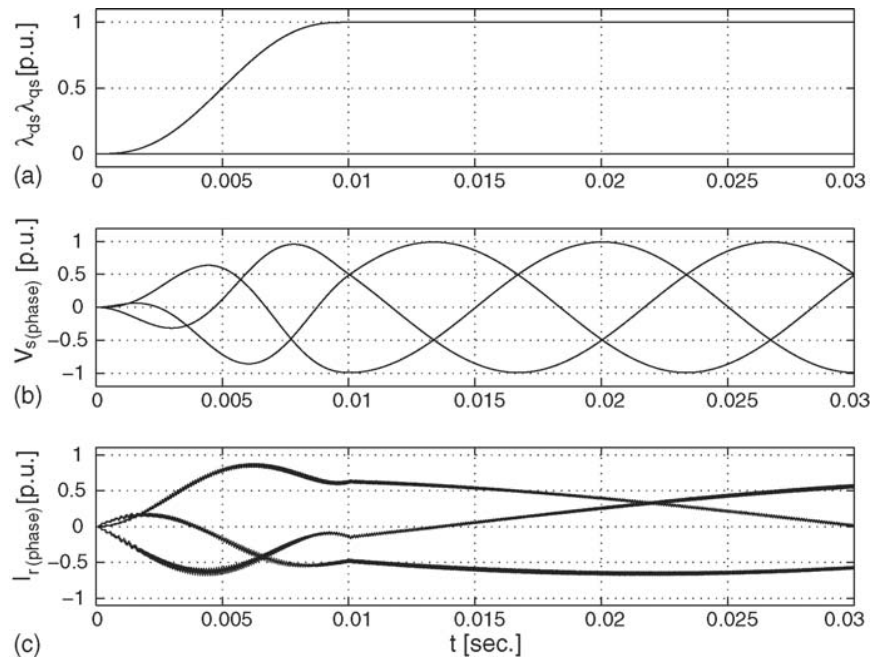

Fig. 4. System turn-on: (a) (-) stator fluxes; (- - -) stator flux references, (b) stator phase voltages and $(\mathrm{c})$ rotor phase currents.

\subsection{System turn-on}

Fig. 4 shows the system turn-on with the reference flux on the direct axis (d) defined as a fifth-order polynomial with first and second derivative continuous. The reference flux on the quadrature axis $(\mathbf{q})$ is set to 0 as it was stated in Eq. (5). It can be observed that the stator fluxes and the stator voltages reaches their nominal values at $10 \mathrm{~ms}$. It is also possible to see that the rotor currents are smooth signals with a small ripple generated by the PWM voltages. It is also seen that the system never reaches saturation.

\subsection{Load change}

The evolution of the system for a load change on the stator terminals is shown in Fig. 5. Initially, the system is loaded with

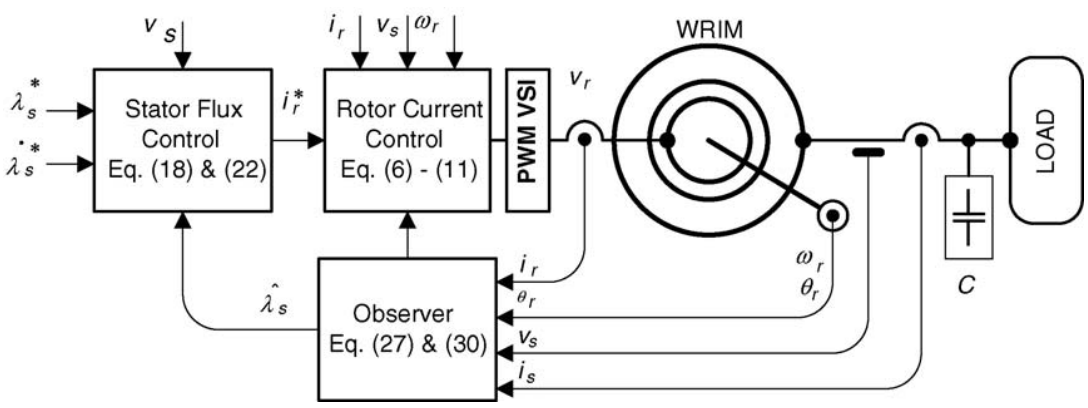

Fig. 3. Simplified block diagram. 


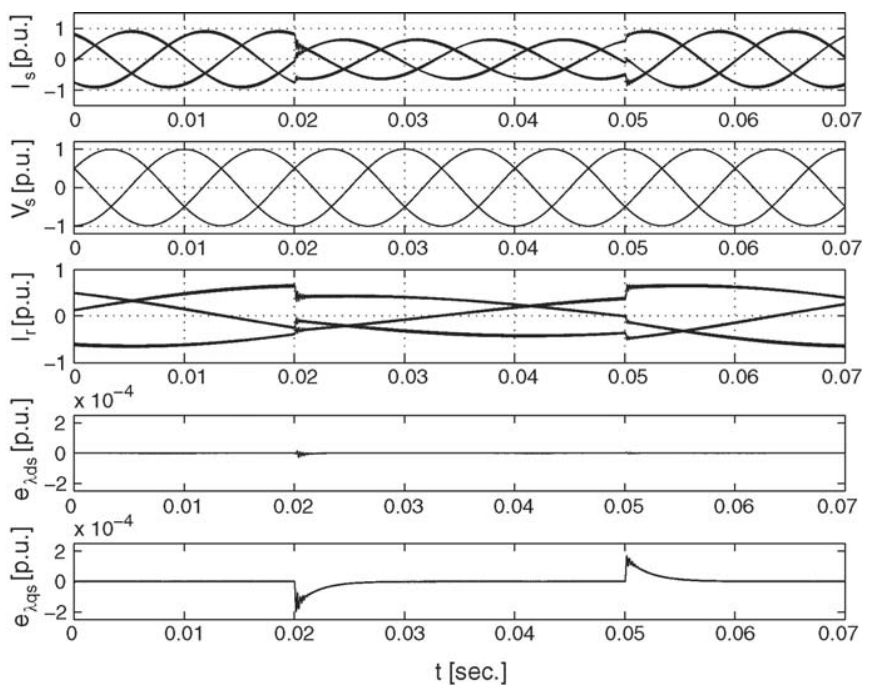

Fig. 5. Load change.

its rated load. At $0.02 \mathrm{~s}$, the load is reduced to 0.5 p.u. and is returned to 1 p.u. at $0.05 \mathrm{~s}$.

No perturbations are observed in the frequency or the stator phase voltages. The error on the flux components does not exceed $2 \times 10^{-4}$ p.u. Even though this error occurs in the quadrature component and it is not possible to compare it with its reference value, $\lambda_{\mathrm{qs}} \simeq 0$, it is more correct to evaluate the phase shift that such error produces. This error implies a maximum phase shift of $2 \times 10^{-4}$ degree, which can be perfectly neglected, concluding then that a load change of even $50 \%$, practically does not affect either the value or the direction of the controlled flux.

Fig. 6 shows a detail of the flux errors shown in the last two graphs of Fig. 5. In addition, the current control errors are intercalated.

It can be observed oscillations on flux errors (with a lower frequency than the PWM switching frequency) that are directly related to the errors on the rotor currents. These oscillations are the result of the interaction between the load (capacitor and
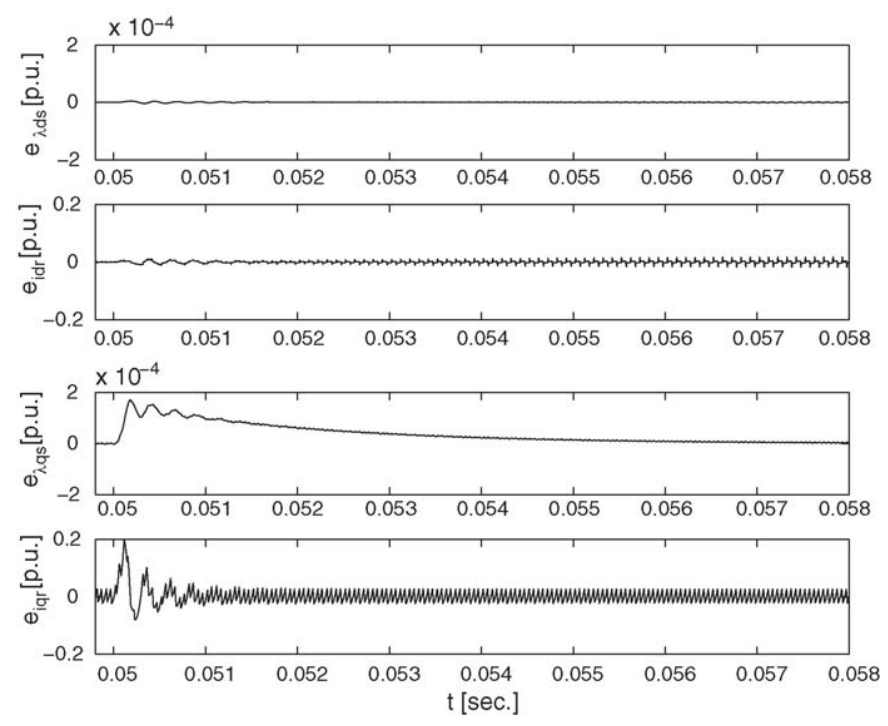

Fig. 6. Current and flux errors.
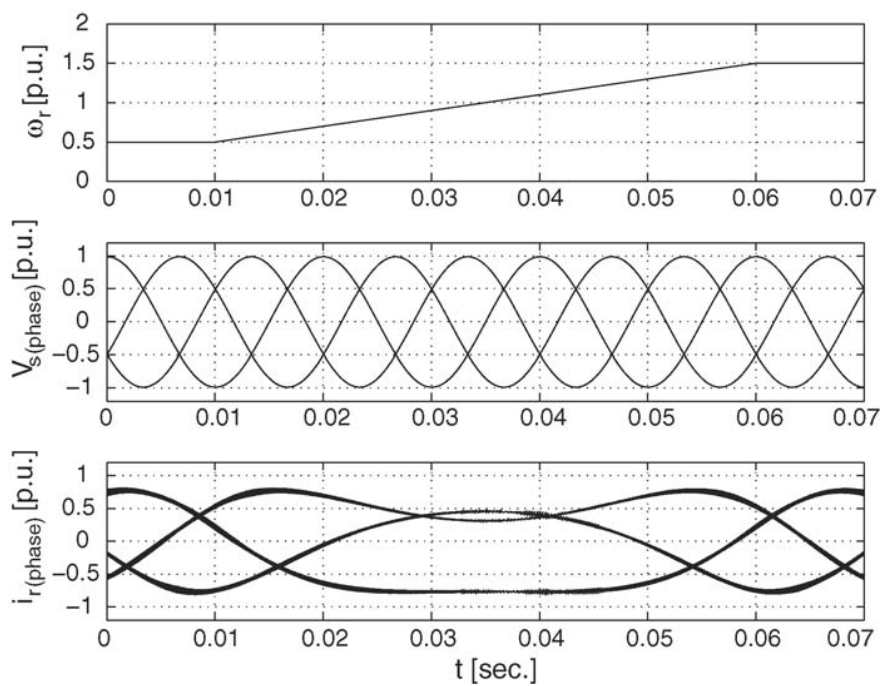

Fig. 7. Speed change.

resistance) and the current control loop. These oscillations decrease as the rotor current loop get faster. On the other hand, the observed exponential decrease is due to the convergence speed of the implemented flux control. The current control loop was designed to have a cut-off frequency five times lower than the PWM switching frequency.

\subsection{Speed change}

Fig. 7 shows the rotor currents and stator voltages during a speed change from 0.5 to 1.5 p.u in $0.5 \mathrm{~s}$ maintaining nominal voltage and load on the machine terminals. The same figure shows that the stator voltage remains unchanged during the transition of speed from sub-synchronic to super-synchronic rotor speed, even when a change in the sequence of the rotor currents occurs. It can be observed that the system behaves smoothly even under circumstances of large speed variations such as $\pm 50 \%$.

\section{Conclusions}

In this paper, a strategy to regulate the voltage and frequency of the wound rotor induction machine was proposed. The stator voltage and frequency regulation was achieved using a rotor current control loop and a stator flux control loop. A stator flux observer was proposed to avoid the use of special sensors. The control loop and observer gains where chosen adequately to make them work well together. It was demonstrated through simulation results that the whole system (controllers and observer) is capable of rejecting perturbations like load change and rotor speed variation (on sub-synchronous, synchronous and supersynchronous regions), keeping the stator voltage and frequency without significant changes.

\section{Acknowledgements}

This work was supported by Universidad Nacional de Río Cuarto (UNRC), Universidad Nacional de La Plata (UNLP), Universidad Nacional del Sur (UNS), ANPCyT and CONICET. 
D. Forchetti has a fellowship from the Consejo Nacional de Investigaciones Cientificas y Técnicas (CONICET). J.A. Solsona, G.O. Garcia and M.I. Valla are members of CONICET.

\section{Appendix A. List of symbols}

\section{$e_{q r}, e_{d r}$ feed forward compensating terms \\ G observer gain matrix}

$i_{\mathrm{qr}}, i_{\mathrm{dr}}$ quadrature and direct rotor current components

$k_{\mathrm{p}}, k_{\mathrm{i}} \quad$ proportional and integral gains

$L_{\mathrm{r}} \quad$ rotor inductance

$L_{\mathrm{S}} \quad$ stator inductance

$M \quad$ magnetizing inductance

$\mathbf{R} \quad$ flux control gain matrix

$r_{\mathrm{r}} \quad$ rotor resistance

$r_{\mathrm{s}} \quad$ stator resistance

$v_{\mathrm{qr}}, v_{\mathrm{dr}}$ quadrature and direct rotor voltage components

$v_{\mathrm{qs}}, v_{\mathrm{ds}}$ quadrature and direct stator voltage components

$x_{\mathrm{qr}}, x_{\mathrm{dr}}$ auxiliary variables

()$^{*} \quad$ reference signals estimated variables

\section{Greek symbols}

$\lambda_{\mathrm{qs}}, \lambda_{\mathrm{ds}}$ quadrature and direct stator flux components

$\omega_{\mathrm{dq}} \quad$ arbitrary reference frame speed

$\omega_{\mathrm{r}} \quad$ rotor speed in electrical radians

\section{References}

[1] D.S. Zinger, E. Muljadi, Annualized wind energy improvement using variable speeds, IEEE Trans. Ind. Appl. 33 (6) (1997) 1444-1447.

[2] A.A. Shaltout, A.F. El-Ramahi, Maximum power tracking for wind driven induction generator connected to a utility network, Appl. Energy (Elsevier) 52 (1995) 243-253.

[3] T. Yifan, X. Longya, A flexible active and reactive power control strategy for a variable speed constant frequency generating systems, IEEE Trans. Power Electron. 10 (4) (1995) 472-478.

[4] E. Bogalecka, Z. Krzeminski, Control systems of a doubly-fed induction machine supplied by current controlled voltage source inverter, in: Proceedings of the Sixth International Conference on Electrical Machines and Drives, Conf. Publ. No. 376, 1993, pp. 168-172.

[5] B. Rabelo, W. Hofmann, Control of an optimized power flow in the wind power plants with doubly-fed induction generators, in: IEEE 34th Power Electronics Specialist Annual Conference, PESC'03, vol. 4, Acapulco, México, 2003, pp. 1563-1568.

[6] W. Hofmann, F. Okafor, Optimal control of a doubly-fed full controlled induction wind generator with high efficiency, in: IECON'01: The 27th Annual Conference of the IEEE Industrial Electronics Society, vol. 2, Denver, CO, EEUU, 2001, pp. 1213-1218.

[7] J. Jayadev, Harnessing the wind, IEEE Spectr. 33 (11) (1995) 78-83.

[8] G.K. Sing, Self-excited induction generator research-a survey, Electr. Power Sys. Res. (Elsevier) 69 (2004) 107-114.

[9] R. Datta, V.T. Ranganathan, Variable-speed wind power generation using doubly fed wound rotor induction machine-a comparison with alternative schemes, IEEE Trans. Energy Convers. 17 (3) (2002) 414-421.

[10] C.R. Kelber, E. Schumacher, Adjustable speed constant frequency energy generation with doubly-fed induction machines, in: European Conference of Variable Speed in Small Hydro, VSSHY2000, Grenoble, Francia, 2000.

[11] S. Müller, M. Deicke, W. Rik, D. Doncker, Doubly fed induction generator systems, IEEE Ind. Electron. Mag. 8 (3) (2002) 26-33.
[12] M.S. Vicatos, J.A. Tegopoulos, Steady state analysis of a doubly-fed induction generator under synchronous operation, IEEE Trans. Energy Convers. 4 (3) (1989) 495-501.

[13] E. Bogalecka, Dynamics of the power control of a double fed induction generator connected to the soft power grid, in: International Symposium on Industrial Electronics, ISIE'93, vol. 8, Budapest, Hungría, 1993, 224 228.

[14] W. Leonhard (Ed.), Control of Electrical Drives, second ed., SpringerVerlang, 1996.

[15] P. Caratozzolo, E. Fossas, J. Pedra, J. Riera, Dynamic modeling of an isolated motion system with DFIG, in: Proceedings of Power Electronics Congress, CIEP 2000, IEEE, Acapulco, México, 2000, pp. $287-$ 292.

[16] Y. Kawabata, T. Oka, E. Ejiogu, T. Kawabat, Variable speed constant frequency stand-alone power generator using wound-rotor induction machine, in: Proceedings of the Power Electronics and Motion Control Conference, IPEMC 2004, IEEE, 2004, pp. 1778-1784.

[17] Y. Kawabata, Y. Morine, T. Oka, E. Ejiogu, T. Kawabat, Variable speed constant frequency power generating system by the use of rotor excitation of induction machine, in: Proceedings of the Power Conversion Conference, PCC, IEEE, Osaka, Japan, 2002, pp. 328-333.

[18] Y. Kawabata, Y. Morine, T. Oka, E. Ejiogu, T. Kawabat, New stand-alone power generation system using wound-rotor induction machine, in: Proceedings of the Fourth IEEE International Conference on Power Electronics and Drive Systems, PEDS2001, vol. 1, IEEE, 2001, pp. 335341.

[19] R.S. Peña, J. Clare, G. Asher, Doubly fed induction generator using backto-back PWM converters and its applications to variable speed wind-energy generation, IEEE Proc. Electron. Power Appl. 143 (3) (1996) 231-241.

[20] R.S. Peña, R. Cardenas, J. Clare, G. Asher, Control strategy of doubly fed induction generators for wind diesel energy system, in: 28th Annual Conference of the IEEE Industrial Electronics Society, IECON02, Sevilla, Spain, 2002, pp. 3297-3302.

[21] R.S. Peña, R. Cardenas, G. Asher, J. Clare, J. Rodriguez, P. Cortes, Vector control of a diesel-driven doubly fed induction machine for a stand-alone variable speed energy system, in: 28th Annual Conference of the IEEE Industrial Electronics Society, IECON02, vol. 2, Sevilla, Spain, 2002, pp. 985-990.

[22] G.C. Verghese, S.R. Sanders, Observers for flux estimation in induction machines, IEEE Trans. Ind. Electron. 35 (1) (1998) 85-94.

[23] P.C. Krause, O. Wasynczuk, S.D. Sudhoff, Analysis of Electric Machinery, IEEE Press, 1996.

[24] H.A. Scottedward, C.E. Hall, Variable-structure PID control to preven integrator windup, IEEE Trans. Ind. Electron. 48 (2) (2001) 442-451.

Daniel G. Forchetti received the Electrical Engineer degree from the National University of Río Cuarto, Argentina, in 1999. In 1996, he had joined the Applied Electronics Group at the National University of Río Cuarto, Argentina, where he is still working. He is currently a Ph.D. student with a fellowship from the National Research Council (CONICET). He is also a member of the Automatic Control Association of Argentina (AADECA). His research interests are in electric machines and drives.

Jorge A. Solsona received the Electronics Engineer and Doctor in Engineering degrees from the National University of La Plata (UNLP), Argentina, in 1986 and 1995, respectively. From 1987 to 1997, he was a member of the Industrial Electronics, Control and Instrumentation Laboratory, Electrical Engineering Department at the Engineering Faculty, of UNLP. He worked in the Electrotechnique Department at the Engineering Faculty of the Comahue National University between 1997 and 2003. Currently, he is with the Electrical Engineering Research Institute "Alfredo Desages" at the Electrical Engineering and Computers Department of the National University of the South and the National Research Council (CONICET). He is engaged in teaching and research in control theory and its applications to electromechanical systems. Dr. Solsona is senior member of the Institute of Electrical and Electronics Engineers and a member of the Automatic Control Association of Argentina (AADECA). 
Guillermo O. García received the Electrical and Electronics Engineering degree from the National University of Cordoba, Argentina, in 1981, the M.Sc. and Doctor in Electrical Engineering from COPPE, Federal University of Rio de Janeiro, Brazil, in 1990 and 1994, respectively. In 1994, he joined the National University of Río Cuarto (UNRC), Argentina. Presently, he is Director of the Applied Electronics Group (GEA), Coordinator of a Graduate Program in Electrical Engineering and professor at the Electrical and Electronics Department of the UNRC. Dr. Garcia is also member of the National Research Council (CONICET) and of the Argentina Automatic Control Association (AADECA). His research interests are in power electronics, motion control, electric vehicles and renewable energy conversion.
María I. Valla received the Electronics Engineering and the Doctor in Engineering degrees from the National University of La Plata (UNLP), Argentina, in 1980 and 1994, respectively. Currently, she is full professor at the Electrical Engineering Department at the Engineering Faculty, of UNLP. She is also member of the National Research Council (CONICET) of Argentina. She is engaged in teaching and research in the area of power converters and ac motor drives. Dr. Valla is Senior member of IEEE, she is senior member of the ADCOM of the IEEE Industrial Electronics Society. She is also member of EXCOM of the Argentina Automatic Control Association (AADECA). She has been member of the organizing committees of several international conferences. 